\title{
TRIADIK
}

ISSN (print): 0853-8301; ISSN (online): 2745-777X

Available online at https://ejournal.unib.ac.id/index.php/triadik

DOI: https://doi.org/10.33369/triadik.v19i2.16410

page: $1-9$

\section{Korelasi antara Hubungan Kelompok Teman Sebaya dan Perilaku Imitasi dengan Gaya Hidup Siswa SMA Negeri 5 Kota Bengkulu}

\author{
1Dewi Lestari, ${ }^{2}$ Hadiwinarto, ${ }^{3}$ Illawaty Sulian \\ 1,2,3Universitas Bengkulu
}

\section{Korespondensi: tari88.dewi@gmail.com}

\begin{abstract}
Abstrak
Penelitian ini bertujuan untuk mengetahui hubungan antara kelompok teman sebaya dan perilaku imitasi dengan gaya hidup. Desain Penelitian ini adalah metode deskriptif kuantitatif dengan teknik korelasi. Populasi penelitian berjumlah 249 dan sampel berjumlah 153 responden. Teknik pengambilan sampel menggunakan simple random sampling. Teknik pengumpulan data melalui angket hubungan kelompok teman sebaya, perilaku imitasi dan gaya hidup. Teknik analisis data menggunakan teknik korelasi product moment dan korelasi ganda. Hasil yang diperoleh dalam penelitian adalah hubungan yang signifikan antara kelompok teman sebaya dengan gaya hidup dengan nilai $\left(\mathrm{rx}_{1} \mathrm{y}\right)$ sebesar 0,240, adanya hubungan negatif yang signifikan perilaku imitasi dengan gaya hidup dengan nilai ( $\left.\mathrm{rx}_{2} \mathrm{y}\right)$ sebesar -0,506 dan adanya hubungan yang signifikan antara kelompok teman sebaya dan perilaku imitasi dengan gaya hidup dengan nilai $\left(\mathrm{Rx}_{1} \mathrm{x}_{2} \mathrm{y}\right)$ sebesar 0,516. Hasil penelitian ini menyimpulkan bahwa adanya hubungan yang signifikan antara hubungan kelompok teman sebaya dan perilaku imitasi dengan gaya hidup siswa.
\end{abstract}

Kata Kunci: Teman Sebaya, Perilaku Imitasi, Gaya hidup

\begin{abstract}
This study aims to determine the relationship between peer groups and imitation behavior with lifestyle. This research design is a quantitative descriptive method with correlation techniques. The study population amounted 249 and the sample amounted to 153. The sampling technique used simple random sampling. Data collection technique was through peer group relationship questionnaire, imitation behavior and lifestyle. The data analysis technique uses the product moment correlation technique and multiple correlation. The results obtained in the study were a significant relationship between peer groups and lifestyle with a value ( $\left.r x_{1} y\right)$ of 0.240 , a significant negative relationship between imitation behavior and lifestyle with a value ( $\left.r x_{2} y\right)$ of -0.506 and a significant relationship between peer groups and imitation behavior with a lifestyle with a value $\left(R x_{1} x_{2} y\right)$ of 0.516. The results of this study concluded that there is a significant relationship between peer group relationships and imitation behavior with students' lifestyle.
\end{abstract}

Keywords: Peer Group, Imitation Behavior, Lifestyle 


\section{Pendahuluan}

Hakikat manusia selain menjadi makhluk individu juga sebagai makhluk sosial, artinya manusia tidak bisa hidup sendiri tanpa kehadiran manusia lain dan akan terus bersosialisasi dengan lingkungan. Sejak lahir individu bergantung kepada orang tua dan keluarga yang memenuhi semua kebutuhan. Masa remaja merupakan masa peralihan dari ketergantungan dan perlindungan orang dewasa pada ketergantungan terhadap diri sendiri dan penentuan diri sendiri (Semiun, 2006:299). Budaya teman sebaya merupakan masa peralihan sebelum sampai pada status orang dewasa dalam masyarakat, perkembangan rasa tanggung jawab sangat tergantung pada kepuasan-kepuasan yang diperoleh dalam kelompok (Semiun, 2006:303). Kelompok sebaya merupakan sumber dukungan emosional yang paling penting sepanjang masa remaja, anak muda yang sedang merasakan perubahan fisik yang cepat akan merasa lebih nyaman dengan sebaya yang mengalami perubahan yang sama (Papalia, 2011:618). Remaja memiliki kebutuhan yang kuat untuk disukai dan diterima teman sebaya atau kelompok. Sebagai akibatnya mereka akan senang apabila diterima dan sebaliknya akan merasa tertekan dan cemas apabila dikeluarkan dan diremehan oleh teman-teman sebayanya (Diananda, 2018:121).

Remaja akan berbagi pengalaman kepada kelompok teman sebaya, berkaitan dengan perubahan yang terjadi, pengalaman melakukan hal baru yang akan membuat anggota kelompok teman sebaya merasakan hal yang sama. Teman sebaya sangat berpengaruh bagi kehidupan remaja, dalam proses interaksinya ini dapat berdampak pada hal yang positif dalam hal ini terjadinya proses belajar bersama (learning together) dan ikut serta dalam kegiatan-kegiatan sosial dan keagamaan. Selain itu, teman sebaya juga bisa memberi pengaruh negatif diantaranya dengan terbentuknya sebuah lifestyle yang tidak baik oleh remaja tersebut. Gaya hidup merupakan cara unik dari setiap orang dalam mencapai tujuan khusus yang telah ditentukan dalam lingkungan hidup tertentu, di tempat orang tersebut berada.

Gaya hidup berdasarkan atas makna yang seseorang berikan mengenai kehidupannya atau interpretasi unik seseorang mengenai inferioritasnya, setiap orang akan mengatur kehidupannya masing-masing untuk mencapai tujuan akhirnya dan mereka berjuang untuk mendapatkan tujuan akhirnya tersebut (Sahrazad, 2016:152). Remaja merupakan kalangan yang paling menarik perhatian di zaman modernisasi, karena remaja dihadapkan pada lingkungan dengan segala sesuatu yang berubah sangat cepat dalam teknologi informasi yang mengakibatkan perubahan nilai serta gaya hidup Harry (dalam Sukarno dkk, 2018:315). Kelompok teman sebaya merupakan faktor yang memiliki pengaruh yang signifikan terhadap gaya hidup remaja. Remaja menghabiskan waktu bersama kelompok teman sebaya cenderung membicarakan hal-hal yang berkaitan seputar makanan, film, musik, video, fashion, aksesoris, cafe terbaru, maupun barang-barang yang sedang menjadi trend dipasaran. Bahkan apabila salah satu dari anggota telah memiliki barang-barang tersebut sering kali menjadi sumber informasi bagi anggota lain.

Perilaku meniru orang lain dikatakan sebagai perilaku imitasi, Bandura (dalam Upton, 2012:19) berpendapat bahwa banyak perilaku manusia di pelajari dengan cara mengamati perilaku dan sikap-sikap orang lain, serta menggunakannya sebagai contoh bagi perilaku kita sendiri (teori 
belajar sosial). Tujuan imitasi adalah individu dapat lebih banyak menguasai respon baru dengan mengamati perilaku orang lain atau model. Selain itu, dengan menerapkan teori ini individu akan cepat menampilkan perubahan sesaat setelah mengamati perilaku orang lain, walaupun pada sebagian besar individu menunjukkan perubahan pada jangka waktu yang lama atau bahkan tidak terjadi perubahan. Tujuan lain imitasi adalah bahwa individu akan mengarahkan perilakunya pada tujuan-tujuan yang ingin dicapainya (selfefficacy) (Barida, 2016:19).

Faktor imitasi menjadi faktor yang sangat mempengaruhi remaja, peningkatan imitasi pada remaja sekarang cenderung tinggi karena remaja dengan mudah melihat model yang akan menjadi objek imitasi remaja. Imitasi yang dilakukan remaja dapat berimplikasi atau berpengaruh secara positif dan negatif.

Studi pendahuluan dilakukan melalui observasi di SMA Negeri 5 Kota Bengkulu karena peneliti melihat adanya indikasi bahwa siswa-siswi di SMA Negeri 5 Kota Bengkulu memiliki kelompok teman sebaya yang mempengaruhi satu sama lain. Peneliti memperoleh hasil bahwa secara umum siswa-siswi di SMA Negeri 5 Kota Bengkulu mempunyai kelompok teman sebaya, dengan latar belakang yang berbeda anggota kelompok akan menunjukkan gaya hidup yang sama dengan anggota kelompok yang lainnya, jika salah satu anggota kelompok mempunyai barang yang sedang trend, maka anggota lainnya berkeinginan untuk membeli.

Hal ini berkaitan dengan perilaku imitasi yang dilakukan siswa untuk meniru gaya hidup yang sedang trend, selain itu remaja ingin mendapatkan pengakuan dari teman sebaya, karena pada proses ini remaja akan mengalami perasaan takut ditolak oleh teman sebaya dan lingkungan sosial jika tidak bisa mengikuti kelompok teman sebayanya. Kelompok teman sebaya akan menunjukkan eksistensi kelompok dengan hal-hal yang sedang trend saat ini, misalnya berpenampilan dengan model pakaian terbaru, secara tidak langsung hal ini akan mempengaruhi gaya hidup siswa.

Pentingnya penelitian ini dilakukan dalam layanan bimbingan dan konseling agar dapat memberikan pemahaman tentang hubungan kelompok teman sebaya dan perilaku imitasi yang sangat penting serta gaya hidup sebagai salah satu faktor yang mempengaruhinya. Berdasarkan kenyataan di atas penulis tertarik untuk melakukan penelitian dengan tujuan untuk mengetahui korelasi antara hubungan kelompok teman sebaya dan perilaku imitasi dengan gaya hidup.

\section{Metode Penelitian}

Metode yang digunakan dalam penelitian ini adalah metode deskriptif kuantitatif dengan teknik korelasi. Populasi dalam penelitian ini adalah seluruh siswa-siswi kelas XII SMA Negeri 5 Kota Bengkulu, dengan jumlah kelas XII MIPA sebanyak enam kelas dan XII SOS sebanyak satu kelas. Jumlah seluruh populasi pada penelitian ini adalah 249 siswa. Teknik pengambilan sampel yang digunakan pada penelitian ini yaitu simple random sampling merupakan sampel yang digunakan secara acak. Sampel pada penelitian ini terbagi menjadi dua, yaitu: sampel uji coba dan sampel penelitian. Sampel uji coba berjumlah 40 orang dan sampel penelitian berjumlah 153 orang. 
Teknik pengumpulan data dalam penelitian ini yaitu menggunakan angket, yang terdiri dari : angket hubungan kelompok teman sebaya, perilaku imitasi, dan gaya hidup dengan model skala likert. Teknik analisis data yang digunakan adalah korelasi ganda, yang dilakukan dengan bantuan aplikasi komputer yaitu program IBM SPSS statistics 22, dengan bantuan aplikasi ini akan diperoleh hubungan antara ketiga variabel dan taraf signifikan dalam menentukan kekuatan dan arah hubungannya. Analisis data yang dilakukan dalam penelitian ini terdiri dari uji validitas, uji reliabilitas, uji normalitas, uji linieritas, dan uji hipotesis.

Langkah awal adalah menguji validitas butir angket dengan melakukan uji coba ke sejumlah responden sampel uji coba dengan menggunakan teknik korelasi product moment. Analisis hasil uji coba pada penelitian ini menggunakan bantuan aplikasi IBM SPSS statistics 22. Berdasarkan hasil uji validitas angket diperoleh hasil bahwa angket hubungan kelompok teman sebaya yang disebarkan ke 40 responden yang terdiri dari 60 item pernyataan didapatkan 2 item yang dinyatakan gugur dan 58 item yang dinyatakan valid. Berdasarkan hasil uji validitas angket diperoleh hasil bahwa angket perilaku imitasi yang disebarkan ke 40 responden yang terdiri dari 60 item pernyataan didapatkan 13 item yang dinyatakan gugur dan 47 item yang dinyatakan valid. Berdasarkan hasil uji validitas angket diperoleh hasil bahwa angket gaya hidup yang disebarkan ke 40 responden yang terdiri dari 61 item pernyataan didapatkan 18 item yang dinyatakan gugur dan 43 item yang dinyatakan valid.

Uji reliabilitas hubungan kelompok teman sebaya, perilaku imitasi, dan gaya hidup ini menggunakan reliability analysis scale (Cronbach's alpha) dengan bantuan aplikasi IBM SPSS statistics 22. Hasil uji reliabilitas menunjukkan hasil bahwa koefisien reliabilitas pada instrument hubungan kelompok teman sebaya yaitu 0,959 , koefisien reliabilitas pada instrument perilaku imitasi yaitu 0,904 dan koefisien reliabilitas pada instrument gaya hidup yaitu 0,901 .

Uji normalitas dalam sebuah penelitian berfungsi untuk menguji normal tidaknya sampel, pengujian dilakukan untuk melihat normal tidaknya sebaran data yang akan dianalisis. Pada penelitian ini uji normalitas dilakukan dengan bantuan aplikasi SPSS versi 22, dengan menggunakan uji normalitas Kolmogorov Smirnov.

Uji linieritas dalam penelitian ini adalah anova, dengan ketentuan signifikansi $5 \%(a=0,05)$. Hipotesis nol ditolak jika $F_{\text {hitung }}>$ F Tabel maka dikatakan kedua variabel tidak linear. Sebaliknya Hipotesis nol diterima jika $\mathrm{F}_{\text {hitung }}<\mathrm{F}_{\text {Tabel }}$ maka dikatakan kedua variabel linear. Uji linieritas dilakukan dengan bantuan aplikasi SPSS 22.

Uji Hipotesis diartikan sebagai jawaban sementara terhadap rumusan masalah penelitian, kebenaran dari hipotesis harus dibuktikan melalui data yang terkumpul. Pengujian hipotesis 1 dan 2 dilakukan dengan korelasi pearson, sedangkan untuk hipotesis 3 dilakukan dengan analisis statistik regresi berganda. Analisis regresi berganda digunakan untuk mengetahui ada tidaknya hubungan antara kelompok teman sebaya dan perilaku imitasidengan gaya hidup pada siswa kelas XII MIPA dan SOS di SMA Negeri 5 Kota Bengkulu. 


\section{Hasil dan Pembahasan}

Deskripsi data yang disajikan pada bagian ini adalah deskripsi tentang masing-masing variabel, yang diteliti antara lain variabel terikat yaitu gaya hidup $(\mathrm{Y})$, variabel bebas hubungan kelompok teman sebaya $\left(\mathrm{X}_{1}\right)$, variabel bebas perilaku imitasi $\left(\mathrm{X}_{2}\right)$. Deskripsi tentang hubungan kelompok teman sebaya, perilaku imitasi dan gaya hidup diperoleh dari hasil penyebaran angket ke sejumlah responden yang menjadi sampel penelitian.

Berdasarkan skor yang diperoleh, didapatkan gambaran tentang skor hubungan kelompok teman sebaya yang dihitung berdasarkan skor ideal, diperoleh gambaran tentang hubungan kelompok teman sebaya dengan skor minimum sebesar 58, skor maximum sebesar 232, rata-rata sebesar 145 , dan standar deviasi sebesar 29. Berikut ini hasil penyusunan kategorisasi penyusunan skor, subjek digolongkan ke dalam tiga kategori hubungan kelompok teman sebaya, yaitu tidak baik, sedang, baik. Secara singkat perhitungan kategorisasi dapat dilihat pada Tabel 1.

\section{Tabel 1. Kategorisasi hubungan kelompok teman sebaya}

\begin{tabular}{cccc}
\hline Kategori & Rentang Skor & Frekuensi & Persentase (\%) \\
\hline Tidak Baik & $58-115$ & - & - \\
Sedang & $116-173$ & 90 & $58,82 \%$ \\
Baik & $174-232$ & 63 & $41,17 \%$ \\
Total & & 153 & $100 \%$
\end{tabular}

Berdasarkan Tabel 1 dapat dilihat bahwa subjek yang memiliki hubungan kelompok teman sebaya sedang sebanyak 90 siswa $(58,82 \%)$ dan subyek yang memiliki hubungan kelompok teman sebaya yang baik sebanyak 63 siswa (41,17\%). Skor perilaku imitasi yang dihitung berdasarkan skor ideal, diperoleh gambaran tentang perilaku imitasi dengan skor minimum sebesar 47 , skor maximum sebesar 188, rata-rata sebesar 117,5, dan standar deviasi sebesar 23,5. Berikut ini hasil penyusunan kategorisasi penyusunan skor, subjek digolongkan ke dalam tiga kategori perilaku imitasi yaitu rendah, sedang, dan tinggi. Secara singkat perhitungan kategorisasi dapat dilihat pada Tabel 2.

Tabel 2. Kategorisasi Perilaku Imitasi

\begin{tabular}{cccc}
\hline Kategori & Rentang Skor & Frekuensi & Persentase (\%) \\
\hline Rendah & $47-93$ & 4 & $2,61 \%$ \\
Sedang & $94-140$ & 131 & $85,62 \%$ \\
Tinggi & $141-188$ & 18 & $11,76 \%$ \\
Total & & 153 & $100 \%$
\end{tabular}

Berdasarkan Tabel 2 dapat dilihat bahwa subjek yang memiliki perilaku imitasi rendah sebanyak 4 siswa $(2,61 \%)$, subjek yang memiliki 
perilaku imitasi sedang sebanyak 131 siswa (85,62 \%) dan subyek yang memiliki perilaku imitasi tinggi sebanyak 18 siswa (11, $76 \%$ ). Skor gaya hidup yang dihitung berdasarkan skor ideal, diperoleh gambaran tentang gaya hidup dengan skor minimum sebesar 43, skor maximum sebesar 172 , rata-rata sebesar 107,5, dan standar deviasi sebesar 21,5. Berikut ini hasil penyusunan kategorisasi penyusunan skor, subjek digolongkan ke dalam tiga kategori gaya hidup yang tergolong tidak baik, sedang, dan baik. Secara singkat perhitungan kategorisasi dapat dilihat pada Tabel 3.

\section{Tabel 3. Kategorisasi Gaya Hidup}

$\begin{array}{llll}\text { Kategori } & \text { Rentang Skor } & \text { Frekuensi } & \text { Persentase (\%) }\end{array}$

$\begin{array}{cccc}\text { Tidak Baik } & 43-85 & 1 & 0,65 \% \\ \text { Sedang } & 86-128 & 113 & 73,85 \% \\ \text { Baik } & 129-172 & 39 & 25,49 \% \\ \text { Total } & & 153 & 100 \%\end{array}$

Berdasarkan Tabel 3 dapat dilihat bahwa subjek yang memiliki gaya hidup yang tergolong tidak baik sebanyak 1 siswa (0,65\%), subjek yang memiliki gaya hidup yang tergolong sedang sebanyak 113 siswa (73,85\%) dan subjek yang memiliki gaya hidup yang tergolong baik sebanayak 39 siswa $(25,49 \%)$. Sebelum menguji hipotesis, terlebih dahulu melakukan uji persyaratan analisis sebagai syarat uji hipotesis dengan jumlah sampel 153 siswa. Uji persyaratan analisis meliputi uji normalitas dan uji linieritas. Hasil uji normalitas One Sample Kolomogrov-Smirnov Test menunjukkan bahwa ketiga variabel yaitu hubungan kelompok teman sebaya, perilaku imitasi, dan gaya hidup memiliki signifikansi sebesar 0,081, 0,055, dan 0,045 dengan $\mathrm{p}>0,05$. Hal ini menunjukkan bahwa ketiga variabel berdistribusi normal. Sedangkan untuk hasil uji linieritas pada variabel hubungan kelompok teman sebaya menunjukkan nilai linieritas pada taraf signifikan sebesar 0,793 dengan $\mathrm{p}>0,05$ (linier), kemudian untuk hasil uji linieritas pada variabel perilaku imitasi menunjukkan nilai linieritas pada taraf signifikan seebesar 0,115 dengan $\mathrm{p}>0,05$ (linier).

Hal ini menunjukkan bahwa terdapat hubungan yang bersifat linier antara hubungan kelompok teman sebaya, perilaku imitasi, dan gaya hidup. Uji hipotesis dilakukan untuk mengetahui apakah ada korelasi ganda yang signifikan antara hubungan kelompok teman sebaya, perilaku imitasi, dan gaya hidup siswa. Uji hipotesis korelasi Product Moment Pearson dan korelasi ganda menggunakan aplikasi IBM SPSS statistics 22. Hasil uji hipotesis dapat di lihat pada tabel 4.

Tabel 4

Matriks Korelasi Antar Variabel

\begin{tabular}{ccc} 
Hubungan & Perilaku & Gaya \\
Kelompok & Imitasi & Hidup \\
Teman & & \\
Sebaya & & \\
\hline
\end{tabular}




\begin{tabular}{|c|c|c|c|c|}
\hline Hubungan & P Pearson & 1 & $278^{* *}$ & $240^{* *}$ \\
\hline Kelompok & Correlation & & & \\
\hline \multirow[t]{2}{*}{ Teman Sebaya } & $\begin{array}{r}\text { Sig. Sig. }(2- \\
\text { tailed) }\end{array}$ & & , 000 & ,003 \\
\hline & $\mathrm{Nh} \mathrm{N}$ & 153 & 153 & 153 \\
\hline Perilaku & Pearson &, $278^{* *}$ & 1 &,$- 506^{* *}$ \\
\hline \multirow{3}{*}{ Imitasi } & Correlation & & & \\
\hline & $\begin{array}{r}\text { Sig. Sig. (2- } \\
\text { tailed) }\end{array}$ & ,000 & &, 000 \\
\hline & NK N & 153 & 153 & 153 \\
\hline \multirow[t]{3}{*}{ Gaya Hidup } & $\begin{array}{l}\mathrm{P} \text { Pearson } \\
\text { Correlation }\end{array}$ &, $240^{* *-}$ &,$- 506^{* *}$ & 1 \\
\hline & ig. Sig. (2-tailed) & ,003 & ,000 & \\
\hline & Nio $\mathrm{N}$ & 153 & 153 & 153 \\
\hline
\end{tabular}

Berdasarkan hasil perhitungan korelasi antara hubungan kelompok teman sebaya dengan gaya hidup menunjukkan koefisien korelasi $\left(\mathrm{r}_{\mathrm{x} 1 \mathrm{y}}\right)$ sebesar 0,240 dengan tingkat signifikansi 0,003 $\mathrm{p}<0,05$ berarti Ho ditolak dan Ha diterima, sehingga terdapat korelasi yang signifikan antara hubungan kelompok teman sebaya dan gaya hidup.Berdasarkan hasil perhitungan korelasi antara perilaku imitasi dengan gaya hidup menunjukkan koefisien korelasi $\left(\mathrm{r}_{\mathrm{x} 2 \mathrm{y}}\right)$ sebesar -0,506 dengan tingkat signifikansi $0,000 \mathrm{p}<0,05$ berarti Ho ditolak dan $\mathrm{Ha}$ diterima, sehingga terdapat korelasi negatif yang signifikan antara perilaku imitasi dan gaya hidup, semakin tinggi perilaku imitasi siswa, maka akan semakin tidak baik gaya hidupnya. Pengujian hipotesis korelasi ganda antara hubungan kelompok teman sebaya $\left(\mathrm{X}_{1}\right)$ perilaku imitasi $\left(\mathrm{X}_{2}\right)$ gaya hidup $(\mathrm{Y})$ perhitungan menggunakan softwere Statistical Packages for Social Science (SPSS) for Window Release 16.00 Product Moment pada tabel 5 sebagai berikut.

\section{Tabel 5} Uji Korelasi Ganda

\begin{tabular}{cccc}
\hline Model & $\mathrm{R}$ & $\mathrm{R}^{2}$ & $\begin{array}{c}\text { Sig F } \\
\text { Change }\end{array}$ \\
\hline 1 & 0,516 & 0,267 & 0,000 \\
\hline
\end{tabular}

Berdasarkan Tabel 5 hasil menunjukkan koefisien korelasi ganda $\left(R_{\mathrm{x} 1 \mathrm{x} 2 \mathrm{y}}\right)$ sebesar 0,516 dengan tingkat signifikansi sebesar 0,000 $(\mathrm{p}<0,05)$. Jika nilai $\mathrm{p}<0,05$ maka Ho ditolak dan $\mathrm{Ha}$ diterima, maka dapat disimpulkan bahwa ada korelasi yang signifikan antara hubungan kelompok teman sebaya dan perilaku imitasi dengan gaya hidup siswa. Koefisien determinasi $\left(\mathrm{R}^{2}\right)$ 0,267 apabila diubah dalam bentuk persentase menjadi 26,7\% artinya hubungan kelompok teman sebaya dan perilaku imitasi mempengaruhi gaya hidup sebesar $26,7 \%$.

Hasil pengujian hipotesis penelitian diperoleh hasil bahwa hubungan kelompok teman sebaya dan perilaku imitasi memiliki hubungan yang signifikan dengan gaya hidup, semakin baik hubungan kelompok teman sebaya dan perilaku imitasi secara bersama-sama, maka semakin baik gaya hidup yang dimiliki siswa. Demikian sebaliknya semakin tidak baik hubungan kelompok teman sebaya dan perilaku imitasi secara bersamasama, maka semakin tidak baik gaya hidup yang dimiliki siswa. Pernyataan 
ini sesuai dengan pendapat Kotler (dalam Rayyan, Bahri, Bakar, 2017:52) yang menyatakan bahwa teman sebaya dapat mempengaruhi seseorang melalui tiga jalur yaitu menghadapkan seseorang pada perilaku gaya hidup baru, mempengaruhi perilaku dan konsep pribadi seseorang serta menciptakan tekanan untuk mengikuti kebiasaan kelompok yang mungkin mempengaruhi pilihan produk. Hubungan kelompok teman sebaya dapat menimbulkan suatu perilaku dimana remaja lebih percaya terhadap teman sebaya dari pada orang tua, teman sebaya mempunyai peranan yang sangat penting dalam membimbing dan mengarahkan kehidupan remaja (Sarmin, 2017:102).

Meskipun manusia sudah banyak belajar dari pengalaman langsung, namun lebih banyak yang mereka pelajari dari aktivitas mengamati perilaku orang lain (Lesilolo, 2018:190). Berdasarkan teori Bandura, faktor kognitif menjadi faktor internal dan lingkungan sebagai faktor eksternal dalam proses belajar untuk memodifikasi perilaku, dan perilaku manusia mewarnai interaksi sosial dalam lingkunganya. Dengan demikian, manusia bukan semata-mata sebagai obyek yang dipengaruhi lingkungan, akan tetapi juga mempengaruhi lingkungan (Tarsono, 2010:29). Siswa yang memiliki perilaku imitasi yang tinggi akan memiliki gaya hidup yang berkaitan dengan model yang ditiru, sebaliknya jika siswa memiliki perilaku imitasi yang rendah akan memiliki gaya hidup tidak sesuai terhadap model yang ditiru.

Menurut Bandura (dalam Upton, 2012:19) individu akan memilih siapa model yang akan ditiru, belajar bukan suatu respons otomatis namun bergantung pada proses-proses internal dan lingkungan. Kita hanya meniru perilaku model jika model tersebut memiliki karakteristik-karakteristik yang kita anggap menarik atau diinginkan. Remaja akan melakukan pengamatan terhadap teman sebayanya, hal ini dilakukan agar remaja bisa mempelajari karakteristik yang dianggap menarik dan dinginkannya, lalu remaja akan mencoba menerapkannya pada dirinya misalnya meniru gaya berbicara, gaya berpakaian dari teman sebayanya agar mendapat pengakuan dan merasa diterima dalam kelompok teman sebayanya. Salah satu ciri remaja adalah meniru semua hal tanpa mempertimbangkan akibatnya, pada masa ini mereka sangat memperhatikan penampilannya dengan teman sebayanya mereka akan berlomba-lomba untuk menjadi yang terbaik dalam berpenampilan (Prasetyo, 2017:122).

Hal ini akan berakibat pada gaya hidup remaja, jika remaja meniru teman sebaya dalam hal negatif tentu akan berdampak negatif terhadap gaya hidup remaja, misalnya teman sebayanya akan memberikan pengaruh secara positif dan negatif. Peranan self-control sangat diperlukan untuk mengontrol perilaku yang ingin ditiru siswa. Self-control yang baik akan mengatur perilaku siswa agar tidak beresiko pada dirinya atau orang lain. Semakin siswa menilai dirinya kurang memuaskan, maka kemungkinan melakukan perilaku imitasi semakin tinggi. Berkaitan dengan hal ini, guru pembimbing adalah guru yang mempunyai tugas, tanggung jawab, wewenang, dan hak secara penuh dalam kegiatan Bimbingan dan Konseling terhadap sejumlah peserta didik, termasuk dalam memberikan layanan Bimbingan dan Konseling kepada semua peserta didik di sekolah tempat dia bertugas dalam rangka mengantarkan peserta didik mencapai pertumbuhan dan perkembangan secara optimal (Umami, 2015:45).

\section{Simpulan}


Kesimpulan dari penelitian ini adalah terdapat korelasi antara hubungan kelompok teman sebaya dan perilaku imitasi dengan gaya hidup siswa SMA Negeri 5 Kota Bengkulu. Nilai koefisien korelasi ganda $\left(R_{\mathrm{x} 1 \mathrm{x} 2 \mathrm{y}}\right)$ sebesar 0,516 dengan tingkat signifikansi sebesar $0,000 \quad(p<0,05)$. Berdasarkan penelitian yang telah dilaksanakan, saran yang dapat diberikan oleh peneliti adalah siswa yang memiliki tingkat perilaku imitasi rendah untuk dapat mempertahankan dan mengontrol dirinya agar tidak mudah meniru perilaku orang lain, jika siswa yang memiliki tingkat perilaku imitasi yang tinggi diharapkan dapat meningkatkan self-control yang dimilki, selain itu dapat berkonsultasi dengan guru BK di sekolah.

\section{Daftar Pustaka}

Barida, M. (2016). Pengembangan perilaku anak melalui imitasi. Jurnal Care Edisi Khusus Temu Ilmiah, 03(3), 13-20.

Diananda, A. (2018). Psikologi Remaja Dan Permasalahannya. Journal ISTIGHNA, 1(1), 116-133. https://doi.org/10.33853/istighna.v1i1.20

Lesilolo, H. J. (2019). Penerapan Teori Belajar Sosial Albert Bandura Dalam Proses Belajar Mengajar Di Sekolah. KENOSIS: Jurnal Kajian Teologi, 4(2), 186-202. https://doi.org/10.37196/kenosis.v4i2.67

Papalia, D. E. (2011). Human Development (Psikologi Perkembangan). Jakarta: Kencana.

Prasetyo, Y. (2017). Gaya Hidup Dan Shopping Addiction. Persona:Jurnal PsikologiIndonesia, 6(2),121-

128.https://doi.org/10.30996/persona.v6i1.1301

Rayyan, Syaiful Bahri, A. B. (2017). Pengaruh Konformitas Teman Sebaya Terhadap Gaya Hidup Experiences. Jurnal Ilmiah Mahasiswa Bimbingan Dan Konseling, 2(1), 48-60.

Sahrazad, S. (2016). Gaya Hidup Dan Motivasi Berprestasi Sebagai Prediktor Terhadap Prestasi Akademik GURU. Sosio-E-Kons, 08(2), 148-159. http://theses.uin-malang/2174/7/08410047_pdf

Sarmin. (2017). Konselor Sebaya: Pemberdayaan Teman Sebaya Dalam Sekolah Guna Menanggulangi Pengaruh Negatif Lingkungan. BRILLIANT:Jurnal Riset Dan Konseptual, 2(1), 102-112.

Semiun, Y. (2017). Kesehatan Mental. Yogyakarta: Kanisius.

Sukarno, N. F., \& Indrawati, E. S. (2018). Hubungan Konformitas Teman Sebaya Dengan Gaya Hidup Hedonis Pada Siswa Di Sma Pl Don Bosko Semarang. Empati, 7(2), 314-320.

Tarsono, T. (2018). Implikasi Teori Belajar Sosial (Social Learning Theory) Dari Albert Bandura Dalam Bimbingan Dan Konseling. Psympathic: Jurnal Ilmiah Psikologi, $3(1), \quad$ 29-36. https://doi.org/10.15575/psy.v3i1.2174

Upton, P. (2012). Psikologi Perkembangan.Jakarta: Erlangga.

Umami, I. (2015). Keterampilan Belajar Sebagai Komponen Layanan Penguasaan Konten dalam Bimbingan dan Konseling. Jurnal Ilmu Pendidikan Psikologis, Bimbingan Konseling, 5(4), 40-50. 